\title{
Predicting the Phase Equilibria of Carbon Dioxide Containing Mixtures Involved in CCS Processes Using the PPR78 Model
}

\author{
Romain Privat and Jean-Noël Jaubert \\ Additional information is available at the end of the chapter \\ http://dx.doi.org/10.5772/57058
}

\section{Introduction}

Carbon dioxide is an extremely important product of the chemical, pharmaceutical and petrochemical industries. Its main applications are production of coal liquids, petroleum processes such as enhanced oil recovery and separation and supercritical fluid extraction. $\mathrm{CO}_{2}$ is however a greenhouse gas that affects the Earth's temperature and many efforts are devoted to the reduction of $\mathrm{CO}_{2}$ emissions. The design and operation of many processes dealing with the $\mathrm{CO}_{2}$ capture and storage (CCS) greatly depend on knowledge about pressurevolume-temperature-composition (PVTxy) and mixing properties $\left(h^{M}, c_{P}{ }^{M}\right)$ of mixtures involved in these processes. A typical $\mathrm{CO}_{2}$ capture and storage (CCS) chain consists of four main steps: $\mathrm{CO}_{2}$ capture, conditioning (dehydration, non-condensable gas separation and/or liquefaction, and compression/pumping), transport and storage.

Carbon dioxide captured from an energy-conversion process always contains impurities that impact the design and operation of CCS systems. The type and amount of the impurities contained into the $\mathrm{CO}_{2}$ depend on the fuels used and the type of capture technology. A nonexhaustive list of these impurities is: $\mathrm{CH}_{4}, \mathrm{H}_{2} \mathrm{~S}, \mathrm{~N}_{2}, \mathrm{O}_{2}, \mathrm{CO}, \mathrm{H}_{2}, \mathrm{COS}, \mathrm{Ar}, \mathrm{SO}_{x}, \mathrm{NO}_{x}, \mathrm{NH}_{3}, \mathrm{SO}_{2}$, amines and $\mathrm{H}_{2} \mathrm{O}$.

Because of the various natures of the impurities encountered in CCS processes and because these processes cover a large range of operating conditions (from atmospheric pressure to supercritical states), it is often necessary to fully guesstimate the phase equilibrium of mixtures $\mathrm{CO}_{2}+$ impurities in both the sub-critical and critical regions by using an appropriate thermodynamic model (this is detailed in section 2.1). In order to meet this objective, Jaubert and Privat developed a group-contribution method (GCM) allowing estimation of the tempera- 
ture-dependent binary interaction parameters $k_{i j}(T)$ for the widely used Peng-Robinson equation of state (EoS). A key point in this approach is that the $k_{i j}$ between two components $i$ and $j$ is a function of temperature $(\mathrm{T})$ and of the pure component critical temperatures $\left(T_{c i}\right.$ and $\left.T_{c j}\right)$, critical pressures $\left(P_{c i}, P_{c j}\right)$ and acentric factors $\left(\omega_{i}, \omega_{j}\right)$. This means that no additional properties besides those required by the EoS itself $\left(T_{c}, P_{c}, \omega\right)$ are needed. The proposed model, named PPR78 for Predictive-Peng-Robinson 1978, can predict any phase equilibrium of mixtures containing $\mathrm{CO}_{2}$ and light alkanes, $\mathrm{N}_{2}, \mathrm{H}_{2}, \mathrm{H}_{2} \mathrm{~S}, \mathrm{H}_{2} \mathrm{O}$.

In this chapter, the ability of the PPR78 model for prediction of $\mathrm{CO}_{2}+$ impurity binary mixtures is discussed and analyzed in terms of phase-equilibrium properties and enthalpies of mixing. The PPR78 model is also applied to the prediction of multicomponent $\mathrm{CO}_{2}$-containing mixtures.

In the first part, the theoretical foundations of the PPR78 equation of state are carefully described. In the second part, the capabilities of the PPR78 model to predict both the global phase behavior (i.e., the phase behavior in both the sub and supercritical area) and the enthalpy data of various binary systems involved in CCS processes are graphically shown and quantitatively assessed.

It is often written in the literature that the greater the number of compounds in a mixture, the more a thermodynamic model may fail in representing its behavior. In that regard, the last part of the chapter deals with multicomponent systems (containing more than two pure species) encountered in CCS processes.

\section{Presentation of the PPR78 thermodynamic model}

\subsection{On the need for an accurate thermodynamic model}

Today, the synthesis design and optimization of CCS processes is carried out with the help of process simulators such as PRO/II, ProSim, HYSIS, ASPEN, UniSim, etc. It is however well known that the accuracy of the simulated results mainly depends on the quality of the chosen thermodynamic model. In most cases, the phase behavior of multicomponent systems, for which nearly no data are available, has to be known. The phase behavior can obviously be measured, but measurements are very time consuming (the VLE measurement of a 10component system at atmospheric pressure in 10 mole $\%$ steps - a total of 92, 378 data points would require 37 years!).

When dealing with fluids involved in CCS processes, many difficulties appear. Indeed, such mixtures contain a large number of various compounds, the proper representation of which involves accurately quantifying the interactions between each pair of molecules. This quantification obviously becomes increasingly difficult, if not impossible, as the number of molecules grows. To avoid such a time-consuming effort, an alternative solution lies in using a thermodynamic model able to estimate the interactions from mere knowledge of the structure of the molecules contained in the blend. 


\subsection{The Equation of State (EoS)}

A few decades ago, Peng and Robinson [1] published their well-known equation of state, called in this chapter PR76. Some years later, the same authors published an improved version of this equation [2], which yields more accurate vapor pressure predictions for heavy hydrocarbons than those obtained by using PR76. This improved equation is called PR78 in this paper. For a pure component, the PR78 EoS is:

$$
P(T, v)=\frac{R T}{v-b_{i}}-\frac{a_{i}(T)}{v\left(v+b_{i}\right)+b_{i}\left(v-b_{i}\right)}
$$

with:

$$
\left\{\begin{array}{l}
R=8.314472 \mathrm{~J} \cdot \mathrm{mol}^{-1} \cdot \mathrm{K}^{-1} \\
X=\frac{-1+\sqrt[3]{6 \sqrt{2}+8}-\sqrt[3]{6 \sqrt{2}-8}}{3} \approx 0.253076587 \\
b_{i}=\Omega_{b} \frac{R T_{c, i}}{P_{c, i}} \text { with } \Omega_{b}=\frac{X}{X+3} \approx 0.0777960739 \\
a_{i}(T)=\Omega_{a} \frac{R^{2} T_{c, i}^{2}}{P_{c, i}}\left[1+m_{i}\left(1-\sqrt{\frac{T}{T_{c, i}}}\right)\right]^{2} \text { with } \Omega_{a}=\frac{8(5 X+1)}{49-37 X} \approx 0.457235529 \\
\text { if } \omega_{i} \leq 0.491 m_{i}=0.37464+1.54226 \omega_{i}-0.26992 \omega_{i}^{2} \\
\text { if } \omega_{i}>0.491 m_{i}=0.379642+1.48503 \omega_{i}-0.164423 \omega_{i}^{2}+0.016666 \omega_{i}^{3}
\end{array}\right.
$$

where $\mathrm{P}$ is the pressure, $\mathrm{R}$ the gas constant, $\mathrm{T}$ the temperature, $\mathrm{a}$ and $\mathrm{b}$ are EoS parameters, $\mathrm{v}$ the molar volume, $\mathrm{T}_{\mathrm{c}}$ the critical temperature, $\mathrm{P}_{\mathrm{c}}$ the critical pressure and $\omega$ the acentric factor. In this chapter, the PR78 EoS is used. To apply such an EoS for mixtures, mixing rules are necessary to calculate the values of $a$ and $b$ of the mixtures.

A widely employed way to extend the cubic EoS to mixtures, the mole fractions of which are $x_{i}$, is via the so-called Van der Waals one-fluid mixing rules [quadratic composition dependency for both parameters] and the classic combining rules, i.e., the geometric mean rule for the cross-energy and the arithmetic mean rule for the cross co-volume parameter:

$$
\left\{\begin{array}{l}
a=\sum_{i=1}^{N} \sum_{j=1}^{N} x_{i} x_{j} a_{i j} \\
b=\sum_{i=1}^{N} \sum_{j=1}^{N} x_{i} x_{j} b_{i j} \\
a_{i j}=\sqrt{a_{i} a_{j}}\left(1-k_{i j}\right) \\
b_{i j}=\frac{1}{2}\left(b_{i}+b_{j}\right)\left(1-l_{i j}\right)
\end{array}\right.
$$


where $a_{\mathrm{i}}$ and $b_{\mathrm{i}}$ denote the EoS parameters for pure component $i, T$ is the temperature, and $N$ is the number of components in the mixture.

Through this, two new parameters, the so-called binary interaction parameters $\left(k_{i j}\right.$ and $\left.l_{i j}\right)$, appear in the combining rules. One of them, namely $k_{i j}$, is by far the most important one. Indeed, a non-null $l_{i j}$ is only necessary for complex polar systems and special cases. This is the reason why, when dealing with petroleum fluids, phase equilibrium calculations are generally performed with $l_{i j}=0$ and the mixing rule for the co-volume parameter simplifies to:

$$
b=\sum_{i=1}^{p} x_{i} b_{i}
$$

Note that the chosen mixing rules are used by most petroleum companies and above all are available in any computational package.

In our approach and in order to define a predictive model, the binary interaction parameters appearing in the mixing rules are calculated by the group-contribution method (GCM), which means that a $k_{i j}$ calculation requires each molecule of a given mixture to be divided into elementary groups of atoms.

$$
k_{i j}(T)=\frac{-\frac{1}{2}\left[\sum_{k=1}^{N_{g}} \sum_{l=1}^{N_{g}}\left(\alpha_{i k}-\alpha_{j k}\right)\left(\alpha_{i l}-\alpha_{j l}\right) A_{k l} \cdot\left(\frac{298.15}{T / K}\right)^{\left(\frac{B_{k l}}{A_{k l}}-1\right)}\right]-\left(\frac{\sqrt{a_{i}(T)}}{b_{i}}-\frac{\sqrt{a_{j}(T)}}{b_{j}}\right)^{2}}{2 \frac{\sqrt{a_{i}(T) \cdot a_{j}(T)}}{b_{i} \cdot b_{j}}}
$$

In Equation (5), $N_{g}$ is the number of different groups defined by the method. In the current state, the PPR78 model can cover a large spectrum of petroleum fluids, from natural gases to crude oils [3-18]. 20 groups exist and make it possible to accurately predict the phase behavior of mixtures containing alkanes, alkenes, aromatic compounds, cycloalkanes, permanent gases $\left(\mathrm{CO}_{2}, \mathrm{H}_{2}, \mathrm{~N}_{2}, \mathrm{H}_{2} \mathrm{~S}\right)$, water and mercaptans.

In this setup, $\alpha_{i k}$ is the fraction of molecule $i$ occupied by group $k$ (occurrence of group $k$ in molecule $i$ divided by the total number of groups present in molecule $i$ ); and $A_{k l}=A_{l k}$ and $B_{k l}=B_{l k}$ (where $k$ and $l$ are two different groups) are constant parameters determined in our previous studies $\left(A_{k k}=B_{k k}=0\right)$.

In order to deal with mixtures containing $\mathrm{CO}_{2}$, light alkanes, $\mathrm{N}_{2}, \mathrm{H}_{2}, \mathrm{H}_{2} \mathrm{~S}$ and $\mathrm{H}_{2} \mathrm{O}$, a set of $\mathrm{N}_{8}$ $=7$ groups is necessary:

1. the methane group $\left(\mathrm{CH}_{4}\right)$

2. the ethane group $\left(\mathrm{C}_{2} \mathrm{H}_{6}\right)$ 
3. the carbon dioxide group $\left(\mathrm{CO}_{2}\right)$

4. the nitrogen group $\left(\mathrm{N}_{2}\right)$

5. the hydrogen sulfide group $\left(\mathrm{H}_{2} \mathrm{~S}\right)$

6. the hydrogen group $\left(\mathrm{H}_{2}\right)$

7. the water group $\left(\mathrm{H}_{2} \mathrm{O}\right)$

Since the carbon dioxide and the impurities are all individually considered as single groups, Equation (5) can be simplified as follows:

$$
k_{12}(T)=\frac{A_{12} \cdot\left(\frac{298.15}{T / K}\right)^{\left(\frac{B_{12}}{A_{12}}-1\right)}-\left(\frac{\sqrt{a_{1}(T)}}{b_{1}}-\frac{\sqrt{a_{2}(T)}}{b_{2}}\right)^{2}}{2 \frac{\sqrt{a_{1}(T) \cdot a_{2}(T)}}{b_{1} \cdot b_{2}}}
$$

where $k_{12}$ is the binary interaction parameter between molecules 1 and 2 .

For these 7 groups, a total of 42 parameters (expressed in $\mathrm{MPa}$ ) were determined. They are summarized in Table 1 [3, 6-9, 13, 15].

\begin{tabular}{|c|c|c|c|c|c|c|c|}
\hline & $\mathrm{CH}_{4}$ & $\mathrm{C}_{2} \mathrm{H}_{6}$ & $\mathrm{CO}_{2}$ & $\mathrm{~N}_{2}$ & $\mathrm{H}_{2} \mathrm{~S}$ & $\mathrm{H}_{2} \mathrm{O}$ & $\mathbf{H}_{2}$ \\
\hline $\mathrm{CH}_{4}$ & 0 & - & - & - & - & - & - \\
\hline $\mathrm{C}_{2} \mathrm{H}_{6}$ & $\begin{array}{l}A=13.04 \\
B=6.863\end{array}$ & 0 & - & - & - & - & - \\
\hline $\mathrm{CO}_{2}$ & $\begin{array}{l}A=137.3 \\
B=194.2\end{array}$ & $\begin{array}{l}A=135.5 \\
B=239.5\end{array}$ & 0 & - & - & - & - \\
\hline $\mathrm{N}_{2}$ & $\begin{array}{l}A=37.90 \\
B=37.20\end{array}$ & $\begin{array}{l}A=61.59 \\
B=84.92\end{array}$ & $\begin{array}{l}A=98.42 \\
B=221.4\end{array}$ & 0 & - & - & - \\
\hline $\mathrm{H}_{2} \mathrm{~S}$ & $\begin{array}{l}A=181.2 \\
B=288.9\end{array}$ & $\begin{array}{l}A=157.2 \\
B=217.1\end{array}$ & $\begin{array}{l}A=134.9 \\
B=201.4\end{array}$ & $\begin{array}{l}A=319.5 \\
B=550.1\end{array}$ & 0 & - & - \\
\hline $\mathrm{H}_{2} \mathrm{O}$ & $\begin{array}{l}A=2265 \\
B=4722\end{array}$ & $\begin{array}{l}A=2333 \\
B=5147\end{array}$ & $\begin{array}{l}A=559.3 \\
B=277.9\end{array}$ & $\begin{array}{l}A=2574 \\
B=5490\end{array}$ & $\begin{array}{l}A=603.9 \\
B=599.1\end{array}$ & 0 & - \\
\hline $\mathrm{H}_{2}$ & $\begin{array}{l}A=156.1 \\
B=92.99\end{array}$ & $\begin{array}{l}A=137.6 \\
B=150.0\end{array}$ & $\begin{array}{l}A=265.9 \\
B=268.3\end{array}$ & $\begin{array}{l}A=65.20 \\
B=70.10\end{array}$ & $\begin{array}{l}A=145.8 \\
B=823.5\end{array}$ & $\begin{array}{l}A=830.8 \\
B=-137.9\end{array}$ & 0 \\
\hline
\end{tabular}

Table 1. Group interaction parameters of the PPR78 model: $\left(A_{k l}=A_{l k}\right) / \mathrm{MPa}$ and $\left(B_{k l}=B_{\mid k}\right) / \mathrm{MPa}$. 
Note that this formulation is very useful for someone having commercial software working with the PR EoS. As shown in one of our previous studies [4], working with hydrocarbon binary mixtures, Equations 4 and 5 are able to predict the different $k_{i j}$ trends commonly encountered. Indeed, $k_{i j}$ may increase, decrease or pass through a minimum with respect to temperature and chain length.

\subsection{On the importance of enthalpy-of-mixing $\left(h^{M}\right)$ data}

Engineers use principles drawn from thermodynamics to analyze and design industrial processes. The application of the first principle (also named energy rate balance) to an open multi-component system at steady state is written as:

$$
\dot{W}+\dot{Q}=\sum \dot{n}_{\text {out }} h_{\text {out }}-\sum \dot{n}_{\text {in }} h_{\text {in }}
$$

where $\dot{W}$ and $\dot{Q}$ are the net rates of energy transfer by work and by heat, respectively; $\dot{n}$ is the molar flowrate and $h$ denotes the molar enthalpy of a stream. Subscripts in and out mean inlet and outlet streams, respectively. Note that kinetic-energy and potential-energy terms were not considered in Equation (7). According to classic thermodynamics, the molar enthalpy of a pcomponent homogeneous system at a given temperature $T$, pressure $P$ and composition $z$ (mole fraction vector) is:

$$
\underset{\substack{\text { molar enthalpy } \\ \text { of an inlet or } \\ \text { an outlet stream }}}{h(T, P, z)}=\sum_{i=1}^{p} z_{i} h_{\text {pure } i}(T, P)+h^{M}(T, P, z)
$$

where $h_{\text {pure } i}(T, P)$ is the molar enthalpy of pure component $i$ at the same temperature and pressure as the mixture, estimated from the PR78 EoS (i.e., the equation of state applied to pure components). $h^{M}(T, P, z)$ is the molar enthalpy change on isothermal and isobaric mixing that will be estimated from the PPR78 model (i.e., the equation of state for mixtures).

From Equations (7) and (8), it thus clearly appears that good estimations of $h^{M}$ data are essential to perform reliable energy balance for CCS processes.

\section{Predicting the phase equilibrium behavior of systems containing $\mathrm{CO}_{2}+$ impurities}

The results obtained by using the PPR78 EoS to reproduce the phase behavior of such systems are graphically shown in this section. In order to numerically evaluate the performances of the model, absolute and relative deviations between experimental data points and their prediction are systematically provided. We now define the different quantities we will refer to hereafter:

- the absolute mean deviation on the liquid phase composition: 


$$
\overline{\Delta x_{1}}=\frac{\sum_{i=1}^{n_{\text {bubble }}}\left(\left|x_{1, \exp }-x_{1, \text { cal }}\right|\right)_{i}}{n_{\text {bubble }}}
$$

- the relative mean deviation on the liquid phase composition:

$$
\overline{\Delta x_{1} \%}=\frac{100}{n_{\text {bubble }}} \sum_{i=1}^{n_{\text {bubble }}} 0.5\left(\frac{|\Delta x|}{x_{1, \exp }}+\frac{|\Delta x|}{x_{2, \exp }}\right)_{\mathrm{i}}
$$

with

$$
|\Delta x|=\left|x_{1, \exp }-x_{1, c a l}\right|=\left|x_{2, \exp }-x_{2, c a l}\right|
$$

- the absolute mean deviation on the gas phase composition:

$$
\overline{\Delta y_{1}}=\frac{\sum_{i=1}^{n_{\text {dew }}}\left(\left|y_{1, \exp }-y_{1, \text { cal }}\right|\right)_{i}}{n_{\text {dew }}}
$$

- the relative mean deviation on the gas phase composition:

$$
\overline{\Delta y_{1} \%}=\frac{100}{n_{\text {dew }}} \sum_{i=1}^{n_{\text {dew }}} 0.5\left(\frac{|\Delta y|}{y_{1, \exp }}+\frac{|\Delta y|}{y_{2, \exp }}\right)_{\mathrm{i}}
$$

with

$$
|\Delta y|=\left|y_{1, \exp }-y_{1, c a l}\right|=\left|y_{2, \exp }-y_{2, c a l}\right|
$$

$n_{\text {bubble }}$ and $n_{\text {dew }}$ are the number of bubble points and dew points, while $x_{1}$ is the mole fraction in the liquid phase of the most volatile component and $x_{2}$ is the mole fraction of the heaviest component. Similarly, $y_{1}$ is the mole fraction in the gas phase of the most volatile component and $y_{2}$ is the mole fraction of the heaviest component. 


\subsection{Phase diagrams of $\mathrm{CO}_{2}+$ light alkane systems}

Mixtures of $\mathrm{CO}_{2}+$ methane have been measured extensively and a huge amount of reliable experimental phase equilibrium and critical data are available in the open literature. To our best knowledge, 424 bubble points, 418 dew points and 17 critical points have been published in the literature. An comprehensive list of references can be found in [6].

Figure 1a shows the isothermal phase diagrams for the system methane(1) $+\mathrm{CO}_{2}(2)$ at six different temperatures. For this system, from low to high temperature the binary interaction parameter varies from 0.093 to 0.112 .

Figure $1 \mathrm{~b}$ is a projection of the critical locus (i.e., the locus of the vapor-liquid mixture's critical points) of this binary system on the $\left(\mathrm{P}_{c^{\prime}} \mathrm{T}_{\mathrm{c}}\right)$ plane. Accurate results are obtained at any temperature although the critical pressure is slightly overestimated at intermediate temperatures.
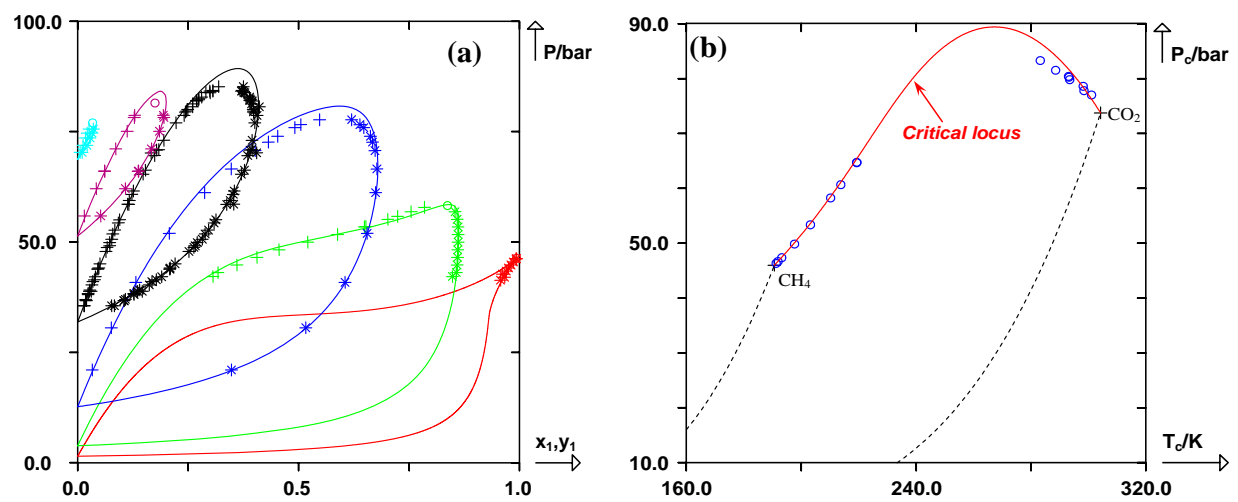

Figure 1. Prediction of isothermal dew and bubble curves and prediction of the critical locus for the binary system (methane $+\mathrm{CO}_{2}$ ) using the PPR78 model. + : experimental bubble points, $*$ : experimental dew points, o: experimental critical points. Solid line: predicted curves with the PPR78 model. Dashed line: vaporization curves of pure compounds. 1a: system methane(1) $/ \mathrm{CO}_{2}(2)$ at 6 different temperatures: $\mathrm{T}_{1}=191.20 \mathrm{~K}\left(k_{i j}=0.0931\right), \mathrm{T}_{2}=210.15 \mathrm{~K}\left(k_{i j}=0.0956\right), \mathrm{T}_{3}=$ $240.00 \mathrm{~K}\left(k_{i j}=0.100\right), \mathrm{T}_{4}=270.00 \mathrm{~K}\left(k_{i j}=0.106\right), \mathrm{T}_{5}=288.50 \mathrm{~K}\left(k_{i j}=0.109\right), \mathrm{T}_{6}=301.00 \mathrm{~K}\left(k_{i j}=0.112\right) .1 \mathrm{~b}:$ critical locus of the methane $/ \mathrm{CO}_{2}$ system.

Mixtures of $\mathrm{CO}_{2}+$ ethane have also been measured extensively. The open literature even offers a few more data than for the $\mathrm{CO}_{2}$ + methane system: 483 bubble points, 438 dew points and 22 critical points. For more details about the references, see reference [6].

Figure $2 \mathrm{a}, 2 \mathrm{~b}$ and $2 \mathrm{c}$ show the isothermal phase diagrams for the system $\mathrm{CO}_{2}(1)+$ ethane(2) at twelve different temperatures. For this system, a homogeneous positive azeotrope always exists. The PPR78 model is able to perfectly predict the phase behavior of this system including the temperature minimum on the critical locus (see Figure $2 \mathrm{~d}$ ).

The deviations observed in both these systems (i.e., $\mathrm{CO}_{2}+$ methane and $\mathrm{CO}_{2}+$ ethane) are: 


\begin{tabular}{ccccccc}
\hline & $\Delta \bar{x}_{1}$ (absolute) & $\Delta \overline{x_{1}} \%$ (relative) & $\Delta \bar{y}_{1}$ (absolute) & $\Delta \overline{y_{1}} \%$ (relative) & $\mathrm{n}_{\text {bubble }}$ & $\mathrm{n}_{\text {dew }}$ \\
\hline $\mathrm{CH}_{4}(1)+\mathrm{CO}_{2}(2)$ & 0.012 & 4.87 & 0.008 & 3.13 & 424 & 418 \\
\hline $\mathrm{C}_{2} \mathrm{H}_{6}(1)+\mathrm{CO}_{2}(2)$ & 0.020 & 6.58 & 0.015 & 4.16 & 483 & 438 \\
\hline
\end{tabular}

Table 2. Absolute and relative mean deviations observed in the $\mathrm{CO}_{2}+$ methane and $\mathrm{CO}_{2}+$ ethane systems.

\subsection{Phase diagrams of $\mathrm{CO}_{2}+\mathrm{N}_{2}$ system}

Mixtures of nitrogen + carbon dioxide have been measured extensively and there is a vast amount of reliable experimental phase equilibrium and critical data (no fewer than 635 VLE data points were found for this system, including the critical points). An accurate list of references can be found in references $[7,8]$. This system is so asymmetrical in terms of size and interactions that its critical locus is no longer continuous (see Figure $3 \mathrm{e}$ ). Such behavior is called Type III according to the classification of Van Konynenburg and Scott [16]. It can be seen that the PPR78 model is able to predict the experimental data with relatively good accuracy. A few examples are shown Figure 3.
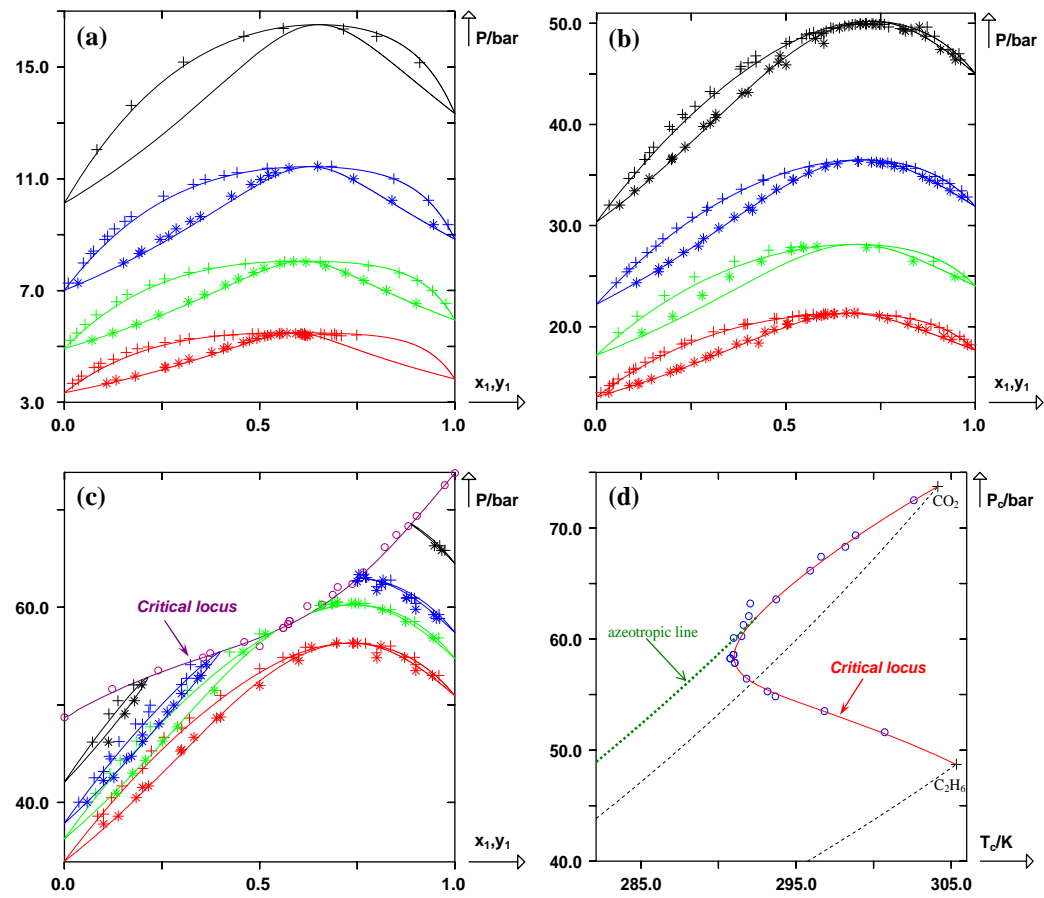

Figure 2. See caption of Figure 1. Dotted line: locus of azeotropic points. 2a: system $\mathrm{CO}_{2}(1) /$ ethane(2) at 4 different temperatures: $\left.\mathrm{T}_{1}=210.00 \mathrm{~K}\left(k_{i j}=0.133\right), \mathrm{T}_{2}=220.00 \mathrm{~K}\left(k_{i j}=0.131\right), \mathrm{T}_{3}=230.00 \mathrm{~K}\left(k_{i j}=0.130\right), \mathrm{T}_{4}=241.45 \mathrm{~K} k_{i j}=0.129\right)$. 2b: system $\mathrm{CO}_{2}(1) /$ ethane(2) at 4 different temperatures: $\mathrm{T}_{1}=250.00 \mathrm{~K}\left(\mathrm{k}_{i j}=0.128\right), \mathrm{T}_{2}=260.00 \mathrm{~K}\left(k_{i j}=0.127\right), \mathrm{T}_{3}=$ $270.00 \mathrm{~K}\left(k_{i j}=0.127\right), \mathrm{T}_{4}=283.15 \mathrm{~K}\left(k_{i j}=0.126\right) .2 \mathrm{c}$ : system $\mathrm{CO}_{2}(1) /$ ethane $(2)$ at 4 different temperatures: $\mathrm{T}_{1}=288.15 \mathrm{~K}$ $\left(k_{i j}=0.126\right), T_{2}=291.15 \mathrm{~K}\left(k_{i j}=0.126\right), \mathrm{T}_{3}=293.15 \mathrm{~K}\left(k_{i j}=0.126\right), \mathrm{T}_{4}=298.15 \mathrm{~K}\left(k_{i j}=0.126\right) .2 \mathrm{~d}$ : critical locus of the $\mathrm{CO}_{2} /$ ethane system. 
Note that in the vicinity of the critical temperature of pure carbon dioxide, the critical locus is perfectly predicted. Similarly to what was observed in the $\mathrm{CO}_{2}+$ methane system, the overestimation of the mixture's critical pressure by the PPR78 model increases when the temperature decreases. In the present case, the binary interaction parameter $k_{i j}$ is a decreasing function of the temperature (see Figure $3 \mathrm{f}$ ). $k_{i j}$ is positive at temperatures lower than $208 \mathrm{~K}$, and negative at temperatures higher than $208 \mathrm{~K}$.
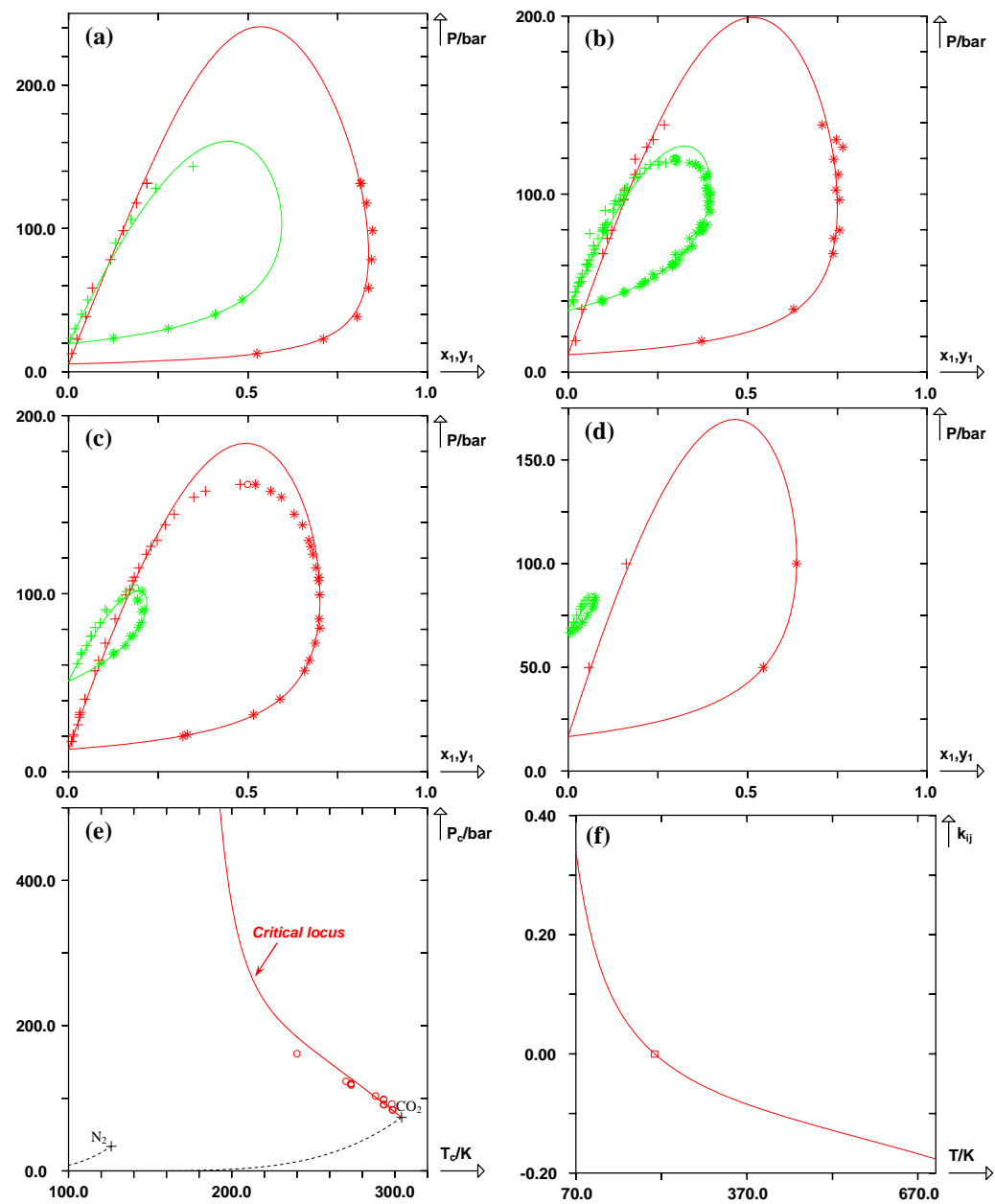

Figure 3. See caption of Figure 1. 8a: System $\mathrm{N}_{2}(1)+\mathrm{CO}_{2}(2)$ at two different temperatures: $\mathrm{T}_{1}=218.15 \mathrm{~K}\left(\mathrm{k}_{\mathrm{ij}}=\right.$ $-0.00856)$ and $\mathrm{T}_{2}=253.15 \mathrm{~K}\left(\mathrm{k}_{i j}=-0.0325\right)$. 8b: System $\mathrm{N}_{2}(1)+\mathrm{CO}_{2}(2)$ at two different temperatures: $\mathrm{T}_{1}=232.85 \mathrm{~K}\left(\mathrm{k}_{i j}=\right.$ $-0.0194)$ and $\mathrm{T}_{2}=273.20 \mathrm{~K}\left(k_{i j}=-0.0437\right) .8 \mathrm{c}$ : System $\mathrm{N}_{2}(1)+\mathrm{CO}_{2}(2)$ at two different temperatures: $\mathrm{T}_{1}=240.00 \mathrm{~K}\left(k_{i j}=\right.$ $-0.0242)$ and $\mathrm{T}_{2}=288.20 \mathrm{~K}\left(k_{i j}=-0.0514\right)$. 8d: System $\mathrm{N}_{2}(1)+\mathrm{CO}_{2}(2)$ at two different temperatures: $\mathrm{T}_{1}=248.15 \mathrm{~K}\left(\mathrm{~K}_{i j}=\right.$ $-0.0294)$ and $\mathrm{T}_{2}=298.80 \mathrm{~K}\left(k_{i j}=-0.0564\right)$. 8e: critical locus. 8f: $k_{i j}$ vs. temperature (the square indicates the temperature at which $\left.k_{i j}=0\right)$. 
The deviations observed in the $\mathrm{N}_{2}+\mathrm{CO}_{2}$ system are:

\begin{tabular}{ccccccc}
\hline & $\begin{array}{c}\Delta \bar{x}_{1} \\
\text { (absolute) }\end{array}$ & $\begin{array}{c}\Delta \overline{x_{1}} \% \\
\text { (relative) }\end{array}$ & $\begin{array}{c}\Delta \bar{y}_{1} \\
\text { (absolute) }\end{array}$ & $\begin{array}{c}\Delta \overline{y_{1}} \% \\
\text { (relative) }\end{array}$ & $\mathrm{n}_{\text {bubble }}$ & $\mathrm{n}_{\text {dew }}$ \\
\hline $\mathrm{N}_{2}(1)+\mathrm{CO}_{2}(2)$ & 0.008 & 6.03 & 0.008 & 2.32 & 320 & 301 \\
\hline
\end{tabular}

Table 3. Absolute and relative mean deviations observed in the $\mathrm{N}_{2}+\mathrm{CO}_{2}$ system.

\subsection{Phase diagrams of $\mathrm{CO}_{2}+\mathrm{H}_{2} \mathrm{~S}$ system}

For this system, 177 bubble points, 176 dew points and 10 critical points were found in the open literature. These references are reported in [9]. Eight predicted isobaric dew and bubble curves are shown in Figure $4 \mathrm{a}$ and $4 \mathrm{~b}$. As can be seen, the PPR78 model is able to predict the behavior of this system with relatively good accuracy. However, as shown by the critical curve displayed in Figure 4c and in accordance with what we previously observed, the PPR78 model tends to overestimate the critical pressures although the absolute deviations remain quite small $(<5$ bar $)$.

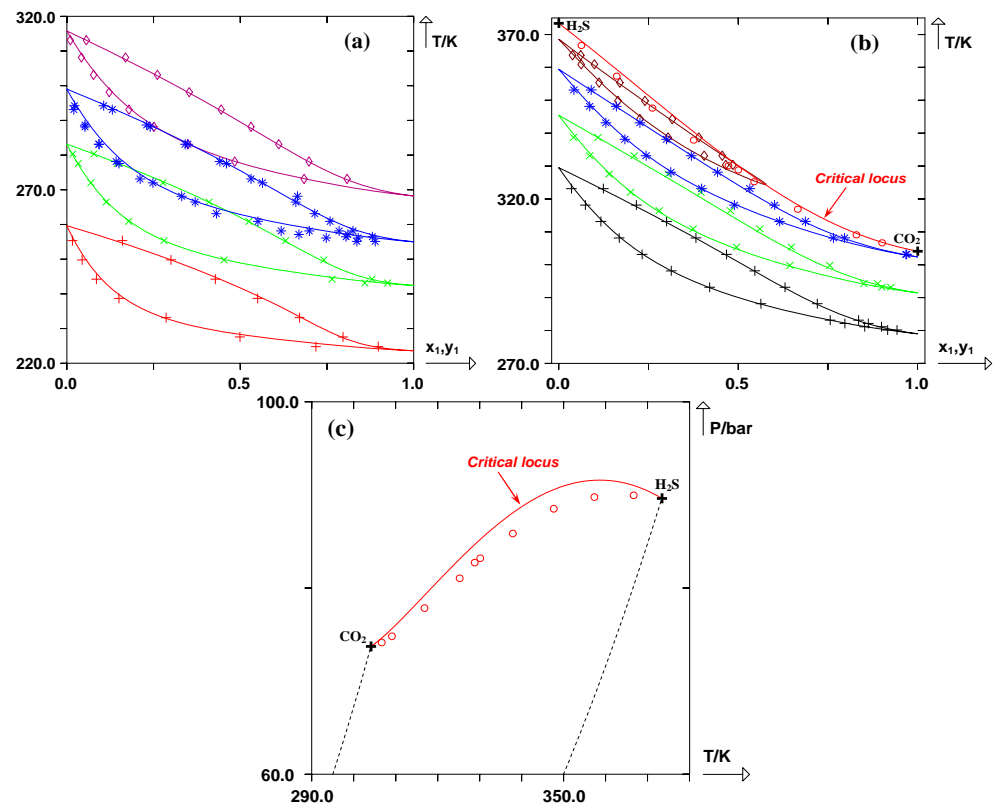

Figure 4. See caption of Figure 1. 4a: System $\mathrm{CO}_{2}(1)+\mathrm{H}_{2} \mathrm{~S}(2)$ at four different pressures: $P_{1}=6.90$ bar, $P_{2}=13.79$ bar, $P_{3}=20.68$ bar, $P_{4}=30.40$ bar. Experimental dew and bubble points at $P_{1}=6.90$ bar $(+), P_{2}=13.79$ bar $(X), P_{3}=20.68$ $\operatorname{bar}(*), \mathrm{P}_{4}=30.40$ bar $(\diamond)$. 4 b: System $\mathrm{CO}_{2}(1)+\mathrm{H}_{2} \mathrm{~S}(2)$ at four different pressures: $\mathrm{P}_{1}=40.53$ bar, $\mathrm{P}_{2}=55.16$ bar, $\mathrm{P}_{3}=$ 70.93 bar, $P_{4}=82.74$ bar. Experimental dew and bubble points at $P_{1}=40.53$ bar $(+), P_{2}=55.16$ bar $(X), P_{3}=70.93$ bar $(*), \mathrm{P}_{4}=82.74$ bar $(\diamond) .4 \mathrm{c}$ : critical locus of the $\mathrm{CO}_{2}(1)+\mathrm{H}_{2} \mathrm{~S}(2)$ system. 
The deviations observed in this system are:

\begin{tabular}{ccccccc}
\hline & \multicolumn{4}{c}{$\bar{x}_{1}$ (absolute) $\Delta \overline{x_{1}} \%$ (relative) $\Delta \bar{y}_{1}$ (absolute) $\Delta \overline{y_{1} \%}$ (relative) } & $n_{\text {bubble }}$ & $n_{\text {dew }}$ \\
\hline $\mathrm{CO}_{2}(1)+\mathrm{H}_{2} \mathrm{~S}(2)$ & 0.009 & 5.13 & 0.008 & 3.06 & 177 & 176 \\
\hline
\end{tabular}

Table 4. Absolute and relative mean deviations observed in the $\mathrm{CO}_{2}+\mathrm{H}_{2} \mathrm{~S}$ system.

\subsection{Phase diagrams of $\mathrm{CO}_{2}+\mathrm{H}_{2}$ system}

Mixtures of $\mathrm{H}_{2}(1)+\mathrm{CO}_{2}(2)$ present many reliable experimental data (302 bubble points, 300 dew points and 11 critical points). For further details, see reference [13]. As shown in Figure $5 \mathrm{a}$, a type III phase behavior is observed for this system. In the vicinity of the critical point of the least volatile component $\left(\mathrm{CO}_{2}\right)$, the critical locus is perfectly predicted (for $\mathrm{T}>250 \mathrm{~K}$ ), as well as the corresponding isothermal $\mathrm{P}-\mathrm{xy}$ phase diagrams (see Figures $5 \mathrm{~b}$ and $5 \mathrm{c}$ ). Once again, critical pressures are systematically overestimated, as highlighted by the isotherms in Figure 5c. Generally, liquid-liquid equilibrium (LLE) and vapor-liquid equilibrium (VLE) data associated with these two binary systems are fairly well predicted over wide ranges of temperature and pressure.

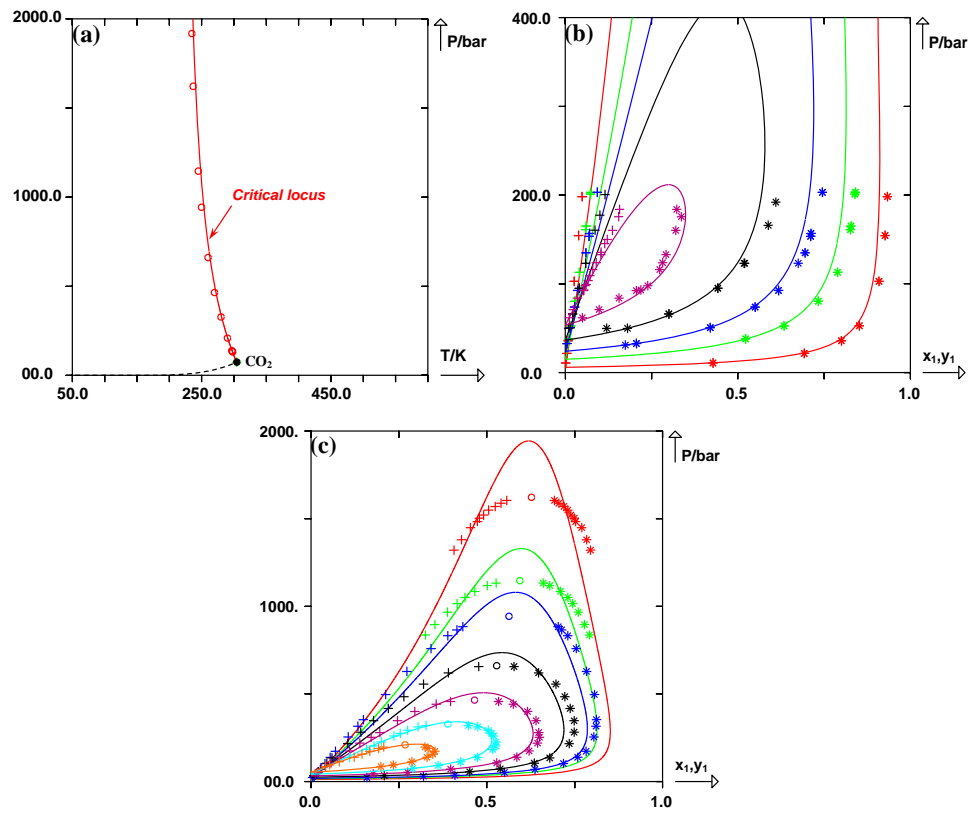

Figure 5. See caption of Figure 1. 5a: prediction of the critical locus of the hydrogen(1) + carbon dioxide(2) system. 5b: prediction of isothermal dew and bubble curves for the system hydrogen(1) + carbon dioxide(2) at five different temperatures: $\mathrm{T}_{1}=219.90 \mathrm{~K}\left(k_{i j}=-0.0211\right), \mathrm{T}_{2}=244.90 \mathrm{~K}\left(k_{i j}=0.0286\right), \mathrm{T}_{3}=259.90 \mathrm{~K}\left(k_{i j}=0.0577\right), \mathrm{T}_{4}=274.90 \mathrm{~K}\left(k_{i j}=\right.$ $0.0865), T_{5}=290.15 \mathrm{~K}\left(k_{i j}=0.1153\right)$. 5c: Prediction of isothermal dew and bubble curves for the system hydrogen( 1$)+$ carbon dioxide(2) at seven different temperatures: $T_{1}=237.00 \mathrm{~K}\left(k_{i j}=0.0130\right), T_{2}=245.00 \mathrm{~K}\left(k_{i j}=0.0288\right), T_{3}=250.00$ $\mathrm{K}\left(k_{i j}=0.0386\right), \mathrm{T}_{4}=260.00 \mathrm{~K}\left(k_{i j}=0.0579\right), \mathrm{T}_{5}=270.00 \mathrm{~K}\left(k_{i j}=0.0771\right), \mathrm{T}_{6}=280.00 \mathrm{~K}\left(k_{i j}=0.0962\right), \mathrm{T}_{7}=290.00 \mathrm{~K}\left(k_{i j}=\right.$ 0.1150). 
The deviations observed in this system are:

\begin{tabular}{ccccccc}
\hline & $\overline{\Delta x}_{1}$ (absolute) & $\Delta \overline{x_{1}} \%$ (relative) & $\Delta \bar{y}_{1}$ (absolute) & $\Delta \overline{y_{1}} \%$ (relative) & $\mathrm{n}_{\text {bubble }}$ & $\mathrm{n}_{\text {dew }}$ \\
\hline $\mathrm{H}_{2}(1)+\mathrm{CO}_{2}(2)$ & 0.018 & 12.8 & 0.018 & 7.11 & 302 & 300 \\
\hline
\end{tabular}

Table 5. Absolute and relative mean deviations observed in the $\mathrm{H}_{2}+\mathrm{CO}_{2}$ system.

\subsection{Phase diagrams of $\mathrm{CO}_{2}+\mathrm{H}_{2} \mathrm{O}$ system}

\subsubsection{On the difficulty to model aqueous systems}

Binary aqueous systems containing hydrocarbons or permanent gases all exhibit vapor-liquid, liquid-liquid and liquid-liquid-vapor equilibria. Here we want to graphically illustrate the well-known dilemma that at a given temperature, the $k_{i j}$ suitable to describe the solubility of $\mathrm{CO}_{2}$ in water is different from the one required to correlate the solubility of water in $\mathrm{CO}_{2}$. By way of example, the phase diagram of the $\mathrm{CO}_{2}(1)+\mathrm{H}_{2} \mathrm{O}(2)$ system is plotted at $\mathrm{T}=298.15 \mathrm{~K}$ in Figure 6.

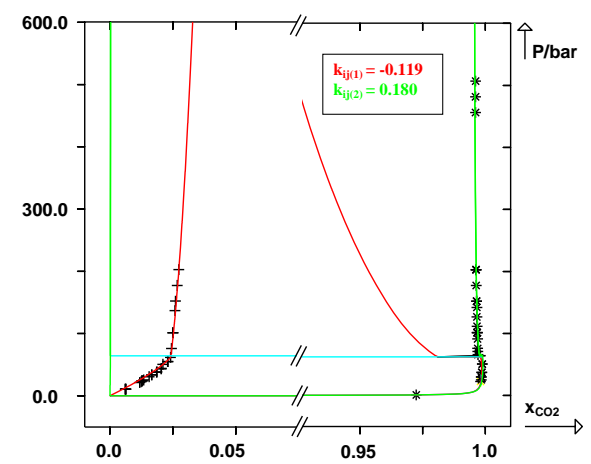

Figure 6. See caption of Figure 1. System $\mathrm{CO}_{2}(1)+\mathrm{H}_{2} \mathrm{O}(2)$ at $\mathrm{T}=298.15 \mathrm{~K}$ with two different $k_{i j}$ values: $k_{i j(1)}=-0.119$ and $k_{i j(2)}=0.180$.

At this temperature, both pure components are subcritical and a three-phase line (locus of liquid-liquid-vapor equilibrium) is found since the temperature of the three-phase critical endpoint, noted CEP (which is the terminating point of the three-phase line) is about $308 \mathrm{~K}$. A negative $k_{i j}$ value of -0.12 perfectly correlates the bubble curve, the dew curve and the solubility of $\mathrm{CO}_{2}$ in water in the liquid-liquid region. On the other hand, such a $k_{i j}$ value fails to correlate the solubility of water in liquid $\mathrm{CO}_{2}$, which can only be captured with a positive $k_{i j}$ value of +0.18 . In order for the PPR78 model to find the best compromise between these two situations, we tried our best to maintain a similar number of data points to describe the solubility of water in the $\mathrm{CO}_{2}$ and the solubility of $\mathrm{CO}_{2}$ in $\mathrm{H}_{2} \mathrm{O}$ respectively. As shown in Figure $7 \mathrm{a}$, for such a system, the PPR78 model predicts $k_{12}=-0.098$. 


\subsubsection{What the PPR78 model can do for such complex systems}

The behavior of the $\mathrm{CO}_{2}+\mathrm{H}_{2} \mathrm{O}$ system has been studied experimentally by different authors (as reported by Qian et al. [15]) in the high-temperature/high-pressure region with value of $539 \mathrm{~K}$ for the minimum temperature of the critical locus beginning at the water critical point. As shown in Figure $7 \mathrm{f}$, reliable predictions of the critical coordinates by the PPR78 EoS are obtained until 4000 bar. As previously discussed, at $\mathrm{T}=298.15 \mathrm{~K}$ (see Figure $7 \mathrm{a}$ ), a $k_{i j}$ value of -0.098 has difficulties in capturing the solubility of water in $\mathrm{CO}_{2}$. Taking into account the scatter of the experimental data, Figure $7 \mathrm{~b}-\mathrm{d}$ highlights that our model predicts the phase behavior of this system with reasonable accuracy.
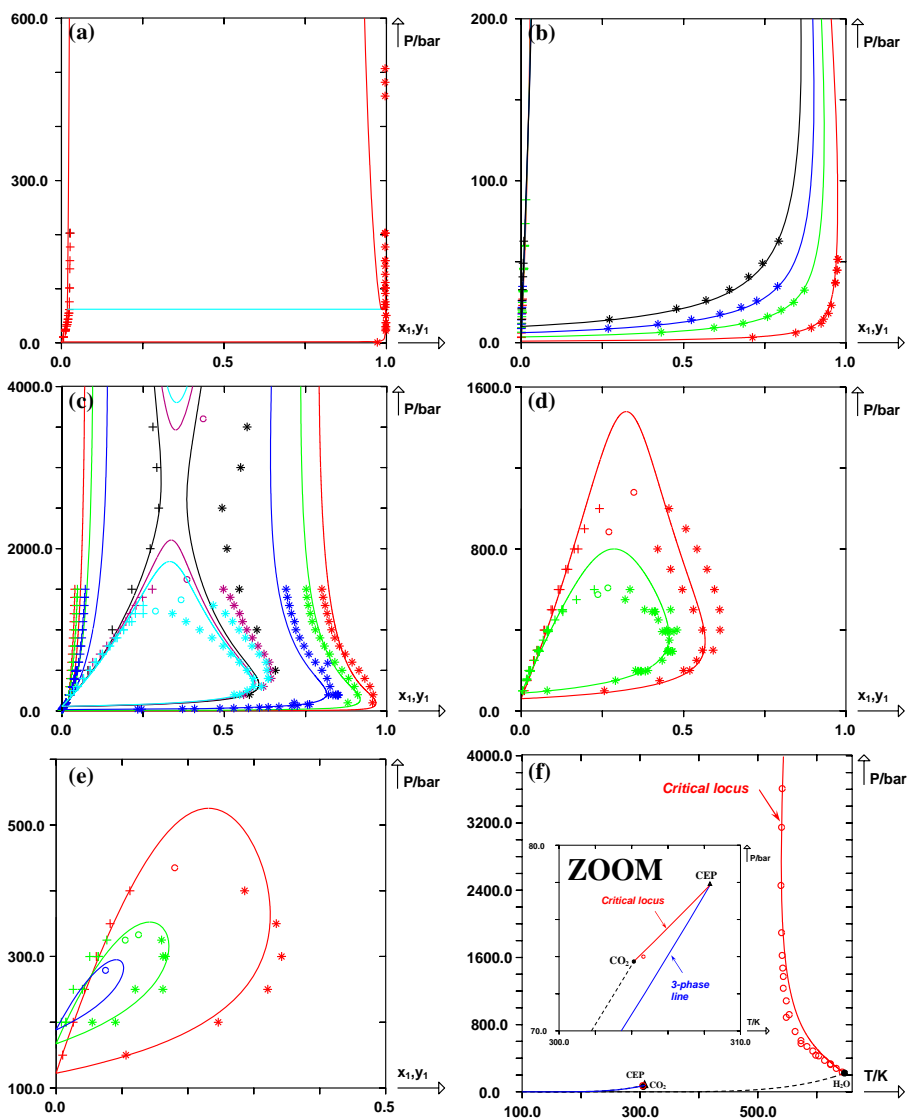

Figure 7. See caption of Figure 1. 7a: System $\mathrm{CO}_{2}(1)+\mathrm{H}_{2} \mathrm{O}(2)$ at $\mathrm{T}=298.15 \mathrm{~K}\left(k_{i j}=-0.098\right)$. $7 \mathrm{~b}$ : System $\mathrm{CO}_{2}(1)+\mathrm{H}_{2} \mathrm{O}(2)$ at four different temperatures: $\mathrm{T}_{1}=373.15 \mathrm{~K}\left(k_{i j}=-0.059\right), \mathrm{T}_{2}=413.15 \mathrm{~K}\left(k_{i j}=-0.036\right), \mathrm{T}_{3}=433.15 \mathrm{~K}\left(k_{i j}=-0.023\right), \mathrm{T}_{4}=$ 453.15 K $\left(k_{i j}=-0.010\right)$. $7 \mathrm{c}$ : System $\mathrm{CO}_{2}(1)+\mathrm{H}_{2} \mathrm{O}(2)$ at six different temperatures: $\mathrm{T}_{1}=383.15 \mathrm{~K}\left(k_{i j}=-0.054\right), \mathrm{T}_{2}=423.15$ $\mathrm{K}\left(k_{i j}=-0.030\right), \mathrm{T}_{3}=473.15 \mathrm{~K}\left(k_{i j}=0.004\right), \mathrm{T}_{4}=538.15 \mathrm{~K}\left(k_{i j}=0.054\right), \mathrm{T}_{5}=541.15 \mathrm{~K}\left(k_{i j}=0.056\right), \mathrm{T}_{6}=543.15 \mathrm{~K}\left(k_{i j}=\right.$ 0.058). 7d: System $\mathrm{CO}_{2}(1)+\mathrm{H}_{2} \mathrm{O}(2)$ at two different temperatures: $\mathrm{T}_{1}=548.15 \mathrm{~K}\left(k_{i j}=0.062\right), \mathrm{T}_{2}=573.15 \mathrm{~K}\left(k_{i j}=0.084\right)$. 7e: System $\mathrm{CO}_{2}(1)+\mathrm{H}_{2} \mathrm{O}(2)$ at three different temperatures: $\mathrm{T}_{1}=598.15 \mathrm{~K}\left(k_{i j}=0.108\right), \mathrm{T}_{2}=623.15 \mathrm{~K}\left(k_{i j}=0.133\right), \mathrm{T}_{3}=$ $633.15 \mathrm{~K}\left(k_{i j}=0.144\right)$. $7 f$ : Critical locus of the $\mathrm{CO}_{2}(1)+\mathrm{H}_{2} \mathrm{O}(2)$ system. 
The deviations observed in this system are:

\begin{tabular}{ccccccc}
\hline & $\overline{\Delta x_{1}}$ (absolute) & $\Delta \overline{x_{1}} \%$ (relative) & $\overline{\Delta y_{1}}$ (absolute) & $\Delta \overline{y_{1}} \%$ (relative) & $\mathrm{n}_{\text {bubble }}$ & $\mathrm{n}_{\text {dew }}$ \\
\hline $\mathrm{CO}_{2}(1)+\mathrm{H}_{2} \mathrm{O}(2)$ & 0.006 & 12.9 & 0.027 & 15.8 & 1068 & 543 \\
\hline
\end{tabular}

Table 6. Absolute and relative mean deviations observed in the $\mathrm{CO}_{2}+\mathrm{H}_{2} \mathrm{O}$ system.

\section{Predicting enthalpies of mixing of $\mathrm{CO}_{2}+$ impurities systems with the PPR78 model}

When molecules are few-polar and few-associating (e.g., in mixtures of alkanes), purecomponent terms provide an excellent estimation of the molar enthalpy of the mixture. Therefore, the enthalpy-of-mixing terms can be seen as a correction, just aimed at improving the first estimation given by the pure-component ground terms. In other words, with fewpolar and few-associating mixtures, $h^{M}$ terms are generally nearly negligible with respect to pure-component terms in the energy rate balance. Typically, $h^{M}$ terms are very small in alkane mixtures (several $\mathrm{J} / \mathrm{mol}$ or several tens of $\mathrm{J} / \mathrm{mol}$ ) but are not negligible in petroleum mixtures containing $\mathrm{CO}_{2}, \mathrm{H}_{2} \mathrm{O}$, alcohols, etc. (likely to reach up to several tens of $\mathrm{kJ} / \mathrm{mol}$ ).

When the parameters involved in the $k_{i j}$ correlations are not directly fitted on enthalpy-ofmixing data (this is, for instance, the case for the PPR78 model), the relative deviations between the calculated and experimental $h^{M}$ data $\left(\overline{\Delta h^{M} \%}\right)$ can be very important and reach values sometimes greater than $100 \%$.

However, since $h^{M}$ quantities are only used to evaluate the molar enthalpies, $h_{\text {in }}$ and $h_{\text {out }}$ involved in the energy rate balance (see Equation (7)), the relative $h^{M}$ deviations do not necessarily matter: only their impact on the accuracy of the energy balance should be actually addressed.

In order to assess how errors in $h^{M}$ may affect the energy balance, we decided to adopt a criterion converting the difference $\Delta h^{M}=\left|h_{\text {calc }}^{M}-h_{\exp }^{M}\right|$ in terms of temperature effect $\Delta T_{h}$ through:

$$
\left\{\begin{array}{l}
\text { For one datapoint: } \Delta T_{h}=\frac{\Delta h^{M}}{c_{P}} \\
\text { For a series of data: } \overline{\Delta T_{h}}=\frac{\sum_{i=1}^{n_{h}}\left(\Delta T_{h}\right)_{i}}{n_{h}}
\end{array}\right.
$$

where $c_{P}$ is the molar isobaric heat capacity of the mixture, and $z_{i}$, the mole fraction of component $i$. 
For all the data, it was possible to find for the considered systems (references are reported in reference [17]), that the deviations are:

\begin{tabular}{ccc}
\hline & $\Delta \bar{T}_{h}(\mathrm{~K})$ & $\begin{array}{c}\text { Number of data } \\
\mathrm{n}_{\text {hM data }}\end{array}$ \\
\hline $\mathrm{CO}_{2}+$ methane & 0.63 & 636 \\
\hline $\mathrm{CO}_{2}+$ ethane & 1.35 & 408 \\
\hline $\mathrm{CO}_{2}+\mathrm{N}_{2}$ & 1.01 & 693 \\
\hline $\mathrm{CO}_{2}+\mathrm{H}_{2} \mathrm{O}$ & 6.88 & 539 \\
\hline
\end{tabular}

Table 7. Prediction of $h^{M}$ data with the PPR78 model for $\mathrm{CO}_{2}$-containing mixtures

Satisfactory results are thus obtained for the first three systems. This leads us to claim that accurate energy balances can be performed with the PPR78 model in processes involving mixtures of carbon dioxide, nitrogen and light alkanes as well.

The $\mathrm{CO}_{2}+\mathrm{H}_{2} \mathrm{O}$ system shows a much more important deviation of around $7 \mathrm{~K}$, which may certainly introduce inaccuracy in an energy balance. However, in mixtures mainly containing $\mathrm{CO}_{2}$ and small proportions of water, errors in the estimation of $h^{M}$ are much more reasonable. The performances of the PPR78 model in terms of $h^{M}$ prediction are illustrated in Figure 8.

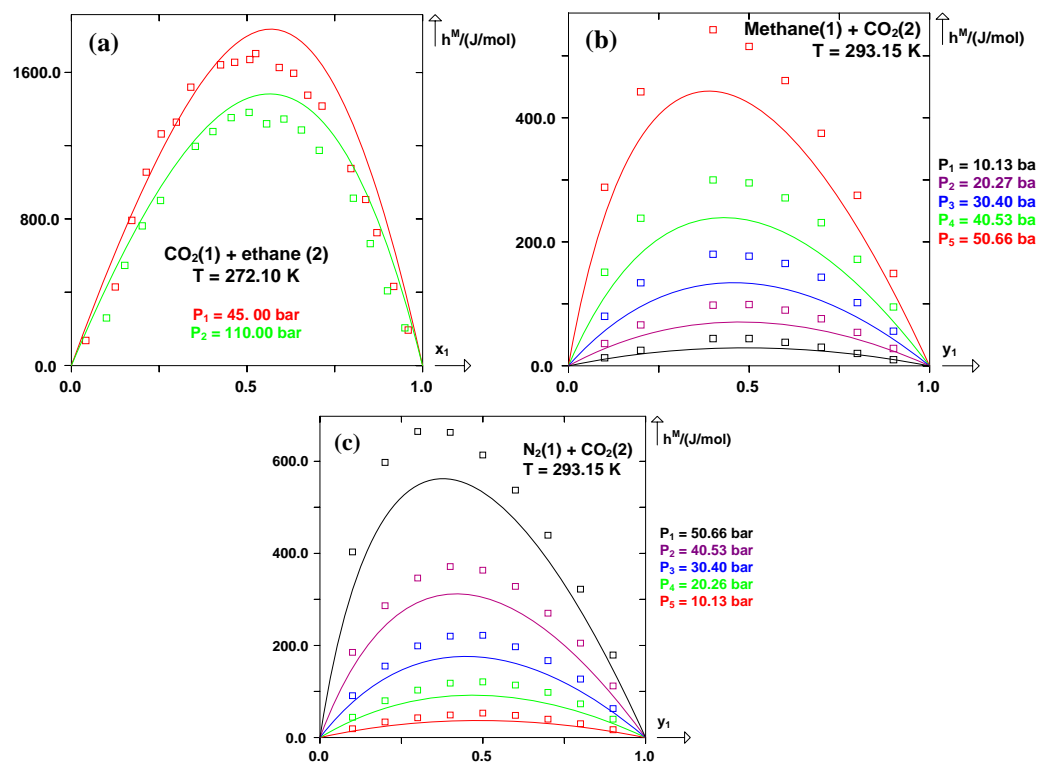

Figure 8. Prediction by the PPR78 EOS of mixing enthalpies of three $\mathrm{CO}_{2}$-containing binary systems. Continuous curves: calculated with the PPR78 model. ( $\square$ ) experimental data. (a) $h^{M}$-curve of a liquid binary system. (b) and (c) $h^{M}$ curves of two gaseous binary systems. 


\section{Predicting the phase behavior of $\mathrm{CO}_{2}$-containing multicomponent systems}

Many phase-equilibrium data have been published on multicomponent $\mathrm{CO}_{2}$-containing mixtures. These mixtures are generally synthetic natural gases containing not only the few molecules studied in this chapter but also light alkanes (generally from methane to hexane). The capability of the PPR78 model is now illustrated in such mixtures. All the references of the experimental datapoints can be found in [12].

a. Yarborough et al.'s fluids.

In 1970, working with 45 different natural gases containing between 2 and 7 components $\left(\mathrm{N}_{2}\right.$, $\mathrm{CO}_{2}$, methane, ethane, propane, $\mathrm{n}$-butane, n-pentane), Yarborough et al. measured 52 bubble and dew-point pressures (the compositions of Yarborough et al.'s fluids are given in [12]). The PPR78 model is able to predict these 52 pressures with an absolute average deviation of 2.0 bar (i.e., 3.2\%) which is certainly close to the experimental uncertainty.

b. Jarne et al.'s fluids.

In 2004, Jarne et al. measured 110 upper and lower dew-point pressures for two natural gases containing nitrogen, carbon dioxide and alkanes up to $n-C_{6}$. The composition of the fluids and the accuracy of the PPR78 model can be seen in Figure 9. The average deviation of these 110 pressures is only 2.0 bar. This is an extremely good result because many data points are located in the vicinity of the cricondentherm, where the slope of the dew curve is very steep.

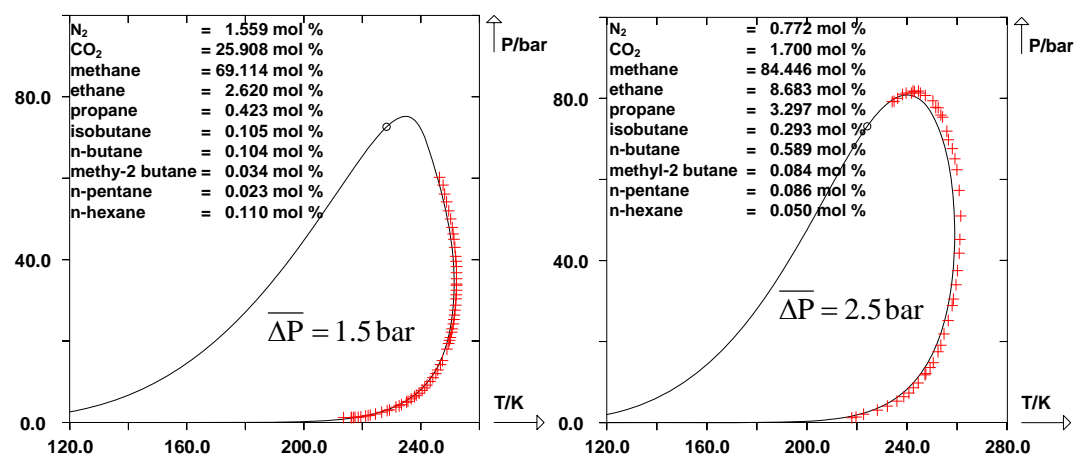

Figure 9. Solid line: $(P, T)$ phase envelopes of Jarne et al.'s natural gases predicted with the PPR78 model. +: experimental upper and lower dew-point pressures. O: predicted critical point.

c. Zhou et al.'s fluid.

In 2006, Zhou et al. measured 6 dew point-pressures for a natural gas containing $\mathrm{N}_{2}, \mathrm{CO}_{2}$ and 7 alkanes. Figure 10 shows that with an average deviation lower than 1.2 bar (i.e., $1.5 \%$ ), the PPR78 model is able to accurately predict these data. 


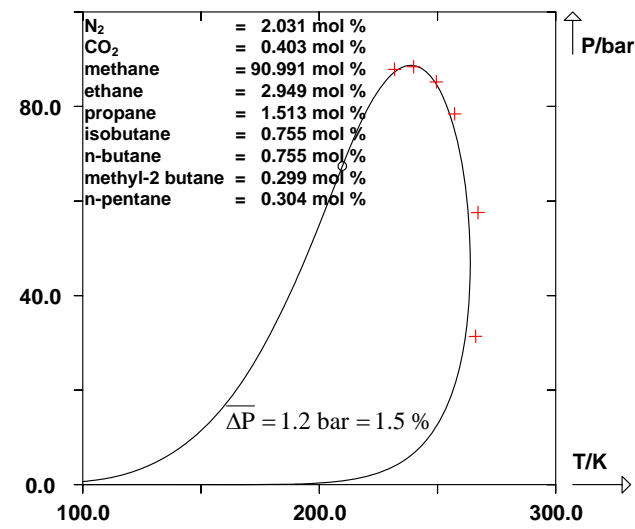

Figure 10. Solid line: $(P, T)$ phase envelopes of Zhou et al.'s natural gas predicted with the PPR78 model. +: experimental upper and lower dew-point pressures. O: predicted critical point.

\section{Conclusion}

This chapter has demonstrated that the PPR78 model is capable of predicting the phase equilibrium behavior of mixtures containing carbon dioxide, light alkanes, nitrogen, hydrogen sulfide, hydrogen and water with good accuracy. This model can also be used to perform energy balance calculations and can be successfully extended to multicomponent mixtures.

Although this chapter shows phase-equilibrium predictions obtained with the PPR78 EoS over the whole composition range (i.e., from $\mathrm{CO}_{2}$-rich to $\mathrm{CO}_{2}$-poor mixtures), $\mathrm{CCS}$ processes essentially involve mixtures containing high proportion of $\mathrm{CO}_{2}$ and small fractions of impurities.

Because PPR78's authors did not want to limit the range of applicability of their model, the A and B parameters involved in the $k_{\mathrm{ij}}$-estimation formula (see Equation (5)) were fitted on all the data we could find in the open literature. Nevertheless, as shown in this chapter, good to excellent predictions can still be obtained for mixtures containing large amounts of $\mathrm{CO}_{2}$.

We believe that the PPR78 model can be safely used to model CCS processes. Whereas interactions between $\mathrm{CO}_{2}$ and impurities were thoroughly described in this chapter, interactions between impurities themselves were not (and are still present in multicomponent mixtures). A proof that a similar quality of predictions can actually be obtained is given in some of the papers mentioned in the bibliographic section $[3,6,7-9,13,15,17]$.

Finally, as a limitation on the use of the PPR78 model, some molecules such as $\mathrm{NH}_{3}, \mathrm{SO}_{2}$ or NOx cannot be presently described by the model. The PPR78 model is currently still under development by its authors and the missing groups should be added in the near future. 


\section{Author details}

Romain Privat and Jean-Noël Jaubert

Ecole Nationale Supérieure des Industries Chimiques, Université de Lorraine, LRGP (Laboratoire Réactions et Génie des Procédés), Nancy, France

\section{References}

[1] Peng, D.Y. \& Robinson, D.B. A New Two-Constant Equation of State. Ind. Eng. Chem. Fundam. 1976;15 59-64

[2] Peng, D.Y. \& Robinson, D.B. The characterization of the heptanes and heavier fractions for the GPA Peng-Robinson programs, Gas processors association, Research report RR-28 1978.

[3] Jaubert, J.N. \& Mutelet, F. VLE predictions with the Peng-Robinson equation of state and temperature dependent $k_{i j}$ calculated through a group contribution method. Fluid Phase Equilib. 2004;224(2) 285-304

[4] Jaubert, J.N.; Vitu, S.; Mutelet, F. \& Corriou, J.P. Extension of the PPR78 model to systems containing aromatic compounds. Fluid Phase Equilib. 2005;237(1-2) 193-211

[5] Vitu, S.; Jaubert, J.N. \& Mutelet, F. Extension of the PPR78 model (Predictive 1978, Peng Robinson EoS with temperature dependent $k_{i j}$ calculated through a group contribution method) to systems containing naphtenic compounds. Fluid Phase Equilib. 2006;243 9-28

[6] Vitu, S.; Privat, R.; Jaubert, J.N. \& Mutelet, F. Predicting the phase equilibria of $\mathrm{CO}_{2}+$ hydrocarbon systems with the PPR78 model (PR EoS and $k_{i j}$ calculated through a group contribution method). J. Supercrit. Fluids. 2008;45(1) 1-26

[7] Privat, R.; Jaubert, J.N. \& Mutelet, F. Addition of the Nitrogen group to the PPR78 model (Predictive 1978, Peng Robinson EoS with temperature dependent $k_{i j}$ calculated through a group contribution method). Ind. Eng. Chem. Res. 2008;47(6) 2033-2048.

[8] Privat, R.; Jaubert, J.N. \& Mutelet, F. Use of the PPR78 model to predict new equilibrium data of binary systems involving hydrocarbons and nitrogen. Comparison with other GCEOS. Ind. Eng. Chem. Res. 2008;47(19) 7483-7489

[9] Privat, R.; Mutelet, F. \& Jaubert, J.N. Addition of the Hydrogen Sulfide group to the PPR78 model (Predictive 1978, Peng Robinson EoS with temperature dependent $k_{i j}$ calculated through a group contribution method). Ind. Eng. Chem. Res. 2008;47(24) 10041-10052

[10] Privat, R.; Jaubert, J.N. \& Mutelet, F. Addition of the sulfhydryl group (-SH) to the PPR78 model (Predictive 1978, Peng-Robinson EoS with temperature dependent $k_{i j}$ 
calculated through a group contribution method). J. Chem. Thermodyn. 2008;40(9) 1331-1341

[11] Privat, R. \& Jaubert, J.N. Addition of the sulfhydryl group (-SH) to the PPR78 model : Estimation of missing group-interaction parameters for systems containing mercaptans and carbon dioxide or nitrogen or methane, from newly published data. Fluid Phase Equilibria. 2012;334 197-203

[12] Jaubert, J.N.; Privat, R. \& Mutelet, F. Predicting the phase equilibria of synthetic petroleum fluids with the PPR78 approach. AIChE J. 2010;56(12) 3225-3235

[13] Qian, J.-W., Jaubert, J.-N., Privat, R. Phase equilibria in hydrogen-containing binary systems modeled with the Peng-Robinson equation of state and temperature-dependent binary interaction parameters calculated through a group-contribution method. J. of Supercritical Fluids 2013;75 58-71

[14] Qian, J.-W., Jaubert, J.-N., Privat, R. Prediction of the phase behavior of alkene-containing binary systems with the PPR78 model. Fluid Phase Equilibria 2013;54 12-235

[15] Qian, J.-W., Privat, R., Jaubert, J.-N. Predicting the phase equilibria, critical phenomena and mixing enthalpies of binary aqueous systems containing alkanes, cycloalkanes, aromatics, alkenes and gases (N2, CO2, H2S, H2) with the PPR78 equation of state. Ind. Eng. Chem. Res. 2013; 52 16457-16490.

[16] Privat, R. \& Jaubert, J.N. Classification of global fluid-phase equilibrium behaviors in binary systems. Chemical Engineering Research and Design 2013; 91 1807-1839

[17] Qian, J.-W., Privat, R., Jaubert, J.-N, Duchet-Suchaux, P. Prediction of enthalpy and heat capacity changes on mixing by means of the PPR78 (Predictive Peng-Robinson, 1978) cubic equation of state. Energy and Fuels 2013; 27 7150-7178.

[18] Jaubert, J.-N. \& Privat, R. Relationship between the binary interaction parameters (kij) of the Peng-Robinson and those of the Soave-Redlich-Kwong equations of state : Application to the definition of the PR2SRK model. Fluid Phase Equilibria 2010; 295(1) 26-37. 